\title{
Education through Applied Learning and Hands-on Practical Experience with Flex Fuel Vehicles
}

\section{Dr. Hazem Tawfik, State University of New York, Farmingdale}

Prof. Tawfik obtained his Ph.D. in Mechanical Engineering, from University of Waterloo, Ontario, Canada. He has held a number of industrial \& academic positions and affiliations with organizations that included Brookhaven National Laboratory (BNL), Rensselaer Polytechnic Institute (RPI), Stony Brook University (SBU), Massachusetts Institute of Technology (MIT), Atomic Energy of Canada Inc., Ontario Hydro, NASA Kennedy, NASA Marshall Space Flight Centers, and the U.S. Naval Surface Warfare Center at Carderock, Md. Dr. Tawfik is the co-author of more than 60 research papers in the areas of Hydrogen Fuel Cells, Biomass Energy, Thermo- fluids and Two Phase Flow published in prestigious peer reviewed journals and conference symposiums. He holds numerous research awards and owns the rights to four patents in the Polymer Electrolyte Membrane (PEM) fuel cells area. Currently, Dr. Tawfik is a SUNY Distinguished Service Professor and the Director of the Institute for Research and Technology Transfer (IRTT) at Farmingdale State College of the State University of New York.

\section{Dr. Yeong Ryu, State University of New York, Farmingdale}

YEONG S. RYU graduated from Columbia University with a Ph.D. and Master of Philosophy in Mechanical Engineering in 1994. He has served as an associate professor of Mechanical Engineering Technology at Farmingdale State College (SUNY) since 2006. In addition, he has conducted various research projects at Xerox Corporation (1994-1995), Hyundai Motor Corporation (1995-1997), and New Jersey Institute of Technology (2001-2003). He has been teaching and conducting research in a broad range of areas of system identification and control of nonlinear mechatronic systems and vibrations in structures requiring precision pointing to eliminate the detrimental effects of such diverse disturbance sources. He has authored or co-authored more than 70 publications. His work currently focuses on the development and implementation of modeling and control of renewable energy systems, characterization of nanomaterials, photovoltaics, and nanoscale integrated systems. He is a member of the American Society of Mechanical Engineers (ASME), American Society for Engineering Education (ASEE) and the Materials Research Society (MRS).

\section{Mr. Rob Kowalski, Farmingdale State College}

Rob Kowalski is a twenty three years old, and currently attending Farmingdale State college as a Mechanical Engineering Student. He works at the Institute for Research Technology Tranfer at Farmingdale. Previously Rob has graduated from Suffolk County Community College with an Associates degree in Automotive Technology and has a background specifically in automotive electronics and emissions. Rob is looking to peruse his future career in Mechanical Engineering within the transportation industry. 


\title{
Education through Applied Learning and Hands-on Practical Experience with Flex Fuel Vehicles
}

\begin{abstract}
The main goal of the work is to perform testing and evaluation of a low horsepower, flex fuel internal combustion engine powered by both liquid and gaseous fuels for comparison and performance optimization. The output horsepower of the internal combustion engine was performed using a dynamo. The tested fuels in the experiment included liquid gasoline, propane, and syngas which is produced from gasifying a woody biomass waste ${ }^{1}$. Since the engine was proven to run on liquid gasoline with known specifications, they were used as a reference baseline for comparison ${ }^{2}$. The engine was converted from liquid gasoline to natural gas using a conversion kit. The engine kit was installed, tuned and tested to run on propane and two types of syngas. Propane performed better but engine modifications are still required to improve the performance running on Syngas ${ }^{3}$.
\end{abstract}

\section{Introduction:}

Due to the fluctuating prices of gasoline numerous attempts are being made to replace or reduce the dependence on gasoline by using other competing fuels such as natural gas, propane, or synthetic gas (syngas). The Institute for Research and Technology Transfer (IRTT) of Farmingdale State College stands as a leading institute for gasification, purification and flex-fuel optimization and therefore syngas is extensively used as fuel in this research work. Our goal is to continue testing and developing internal combustion engines to run on cost effective flex fuels. Running internal combustion engines on different biomass gasses or flex fuels is a technique that has been used from time to time since as early as the 1920's. During this time following the First World War, conventional gasoline was at a shortage across the nation and engineers across the automotive industry started testing different fuel types as an alternative to gasoline. One alternative that gained popularly was the use of biomass gas, also known then as wood gas. This wood gas was created by furnaces that were physically attached to the automobile. When the wood was burned in the furnace, the resulting gas was then captured, and used in the internal combustion engine of the automobile. Although this method was crude and unrefined compared to today's biomass gas standards, it was the start of a method of powering internal combustion engines using renewable energy. With the demand for renewable energy sources at an all-time high, the knowledge of this technique can help us develop and test newer biomass-fuel engines that are not only cleaner, but more efficient and produce more power than those systems used over 90 years $\mathrm{ago}^{4}$.

Therefore, the IRTT installed a kit to enable a one piston cylinder internal combustion engine (to run on propane gas. In addition, a secondary experiment was performed to test the engine power output as well as factors such as efficiency and durability. In order to obtain measurements of power output, the engine was installed onto a rolling chassis dynamometer. The conclusions 
from these tests yielded high accuracy horsepower measurements; however more importantly for the applied research work, all the data collected was done within a hands-on and highly dynamic learning environment. This type of applied learning comes with many benefits in comparison to traditional learning in a classroom setting. One of the main benefits is that the student can immediately learn by physically doing and then see the impact of a scientific or engineering theory on a subject in a real-world application. Furthermore, the experiments were designed to give the students a sense of what it would be like to work as a professional and prepare them for post-graduation career opportunities. Giving the students such hands-on experience proved to be invaluable because this type of applied learning is very similar to how the industry operates on a daily basis in the research and development environment.

\section{Procedure:}

The students began their investigation by determining a Briggs \& Stratton 1450 series horizontal OHV Engine's capability in running on a synthetic gas mixture, since its carburetor is well suited for needed modifications that allow changing the air-fuel ration. Two mixtures of synthetic gas cylinders were used in this study, the first contained 20\% Carbon Monoxide (CO), 10\% Carbon Dioxide $\left(\mathrm{CO}_{2}\right), 50 \%$ Nitrogen $(\mathrm{N})$ and $20 \%$ Hydrogen $(\mathrm{H})$ the second contained $10 \% \mathrm{CO}_{2}, 50 \%$ $\mathrm{N}$ and $40 \% \mathrm{H}$. Both tanks were used for this project to determine the effectiveness of varying hydrogen percentages, on the internal combustion engine's performance.

The internal combustion process begins at the carburetor (Figure 1). Air enters the carburetor through the air intake system which includes the air cleaner and attached intake manifolds. The amount of air entering the engine is regulated using the combination of a choke valve and throttle plate. As the air enters the intake system it is pushed past the venturi. At this point, a vacuum is created which pulls fuel from the jet at a specific air to fuel ratio depending on the amount of vacuum created within the venturi. This mixture of vaporized liquid fuel and air is then compressed by the piston in the cylinder, then ignited by the spark plug once peak cylinder pressure is obtained. The resulting combustion forces the cylinder down the block on the power stroke. This resulting process of combustion and force is what creates the power in the internal combustion engine. The energy produced through this process is converted to work through the piston and rotating motion of the crankshaft. The rotating crankshaft's work produced in the form of rotational torque has the ability to now transfer power to a multitude of different components, from power take offs to power transmission systems ${ }^{5}$. 


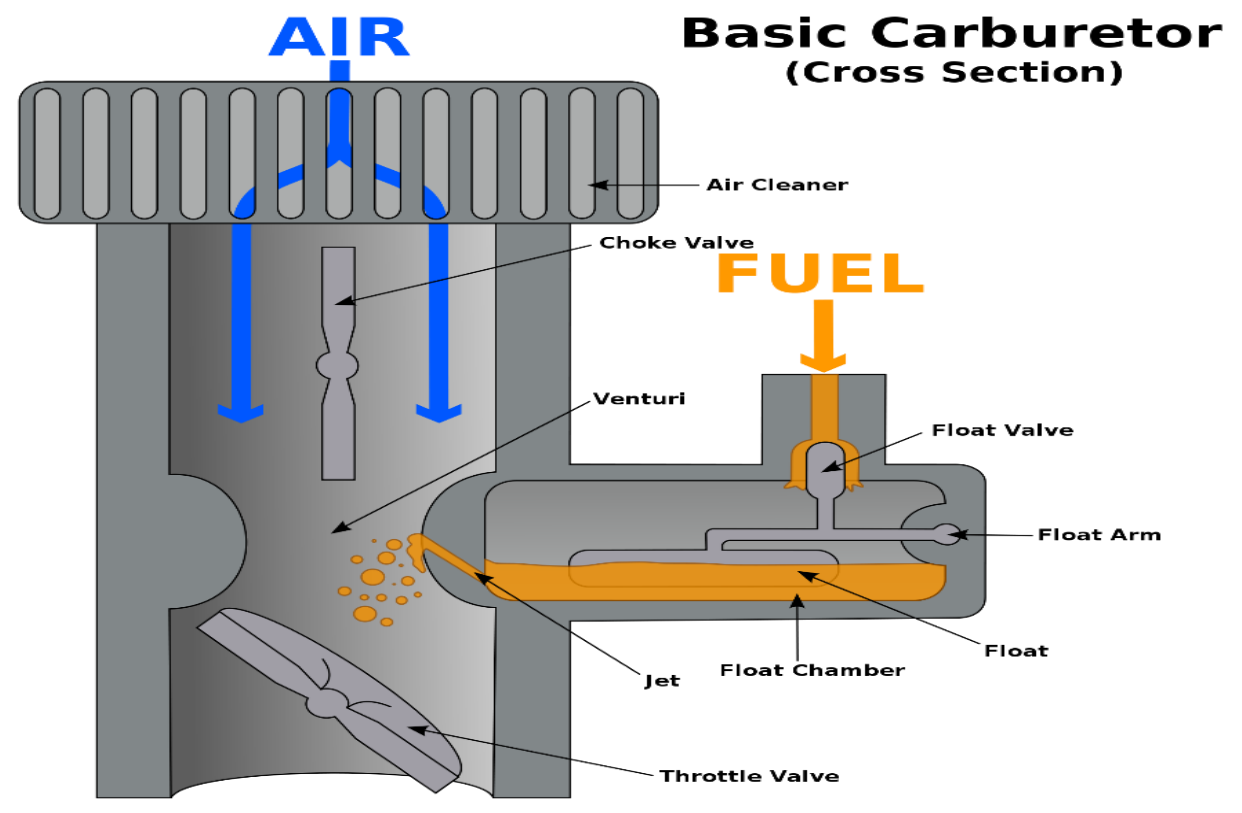

Figure 1: Carburetor Cross Section ${ }^{6}$

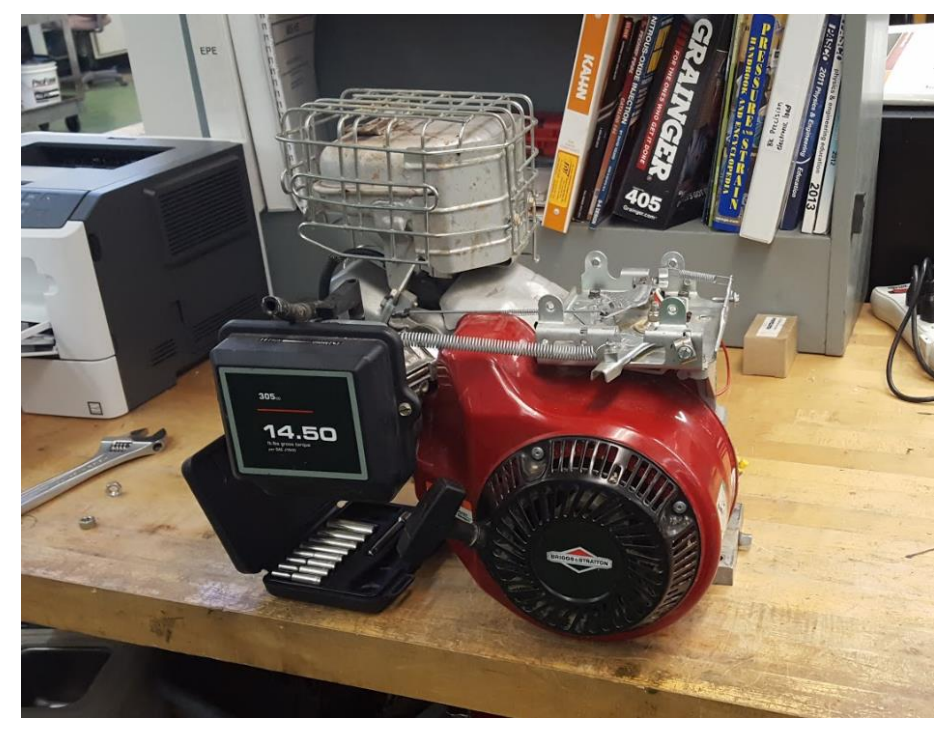

Figure 2: Briggs \& Stratton single cylinder engine

As indicated earlier, the engine used for this project is a Briggs \& Stratton 1450 Series over-head valve engine donated for use by the Society of Automotive Engineers Baja club (Figure 2). To begin the setup of the engine, a universal mounting plate was utilized to mount a plywood board that had been placed onto a movable cart. The engine was placed on top of the plate and secured using 4 bolts. 
The engine was tested using three different gases which included propane and two mixtures of synthetic gas that are currently available and produced at the IRTT.

\section{Propane Testing Setup:}

The project began by testing the effectiveness of the engine using propane. A propane conversion kit that was utilized for this project. The conversion kit included a Century Fuel Product, C-039-122 Low Pressure Regulator (Figure 3). The regulator works on the vacuum that is created in the engine, which acts on the internal diaphragm and through the outlet of the regulator. The diaphragm is forced towards the vacuum made by the atmospheric pressure that enters the carburetor. The lever is depressed which pulls the valve seat away from the orifice. This allows the propane fuel to flow until the vacuum ceases. A primer is also built into the regulator for easy starting of the internal combustion engine. This includes a spring loaded button that when pressed, pushes on the lever and forces the valve in the orifice open ${ }^{7}$.

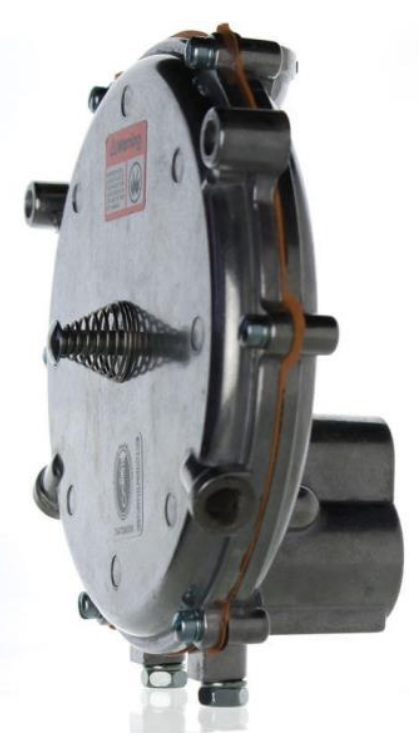

Figure 3: Low Pressure Regulator ${ }^{8}$

To begin testing, the diaphragm was first mounted to the engine cart (Figure 4). The diaphragm outlet makes a connection to the engine via a half-inch rubber hose, with a special orifice fitting that opens into the carburetor. An elbow pipe, a shut-off valve and a pressure gauge were connected at the inlet end of the diaphragm. Another pressure gauge was connected to the regulator, using a ball release valve and a 90-degree elbow. The purpose of the shut-off valve is to regulate when the propane can enter the pressure regulator of the engine. 


\section{Propane Engine Testing:}

Initial testing of the engine on propane was unsuccessful. A loose fitting was discovered during the initial testing and was thought to be the cause. However, further testing resulted in no immediate effect on the performance of the engine. The engine would engage for a few seconds but immediately shut off. It was observed that the pressure was dropping to $0 \mathrm{psi}$, at the pressure gauge attached to the diaphragm. It was determined that the filter was covered with oil, and dirt resulting in clogged air filter caused a lack of air flow entering the carburetor. The low air flow into the carburetor caused too little propane to flow into the combustion chamber, resulting in a no-start condition. The engine began to run perfectly after the removal of the air filter. The performance of the engine was most effective at approximately 2 psi (Figure 4). The group concluded that the increase in air flow enabled a higher vacuum to be created in the engine. This vacuum caused the diaphragm to open more, flowing more propane into the engine to provide steady and continuous operation.

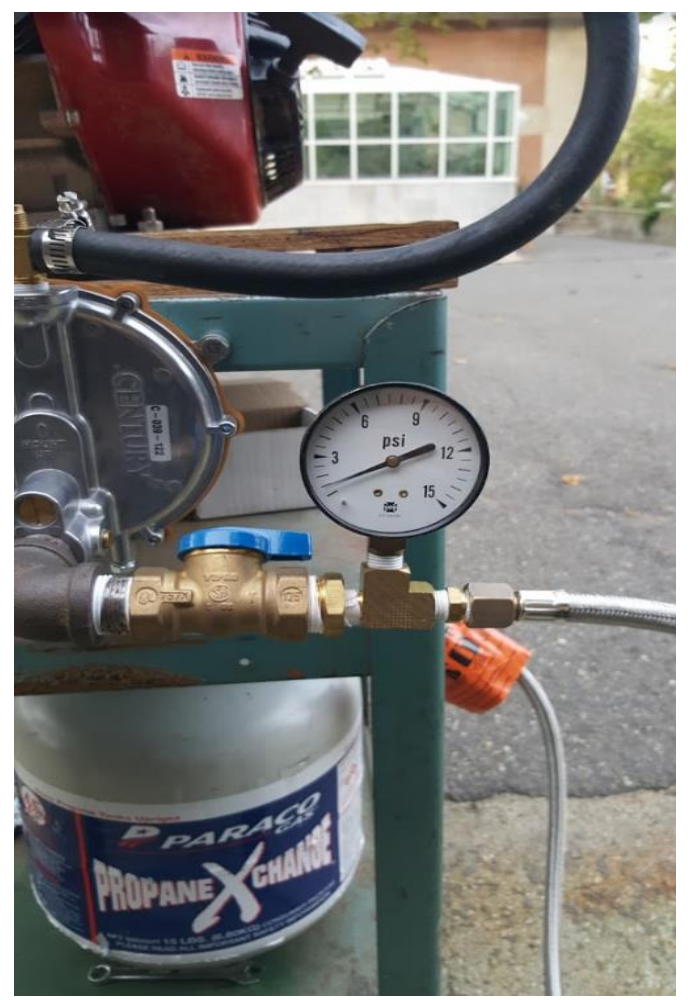

Figure 4: Propane Engine Test 


\section{Synthetic Gas Testing:}

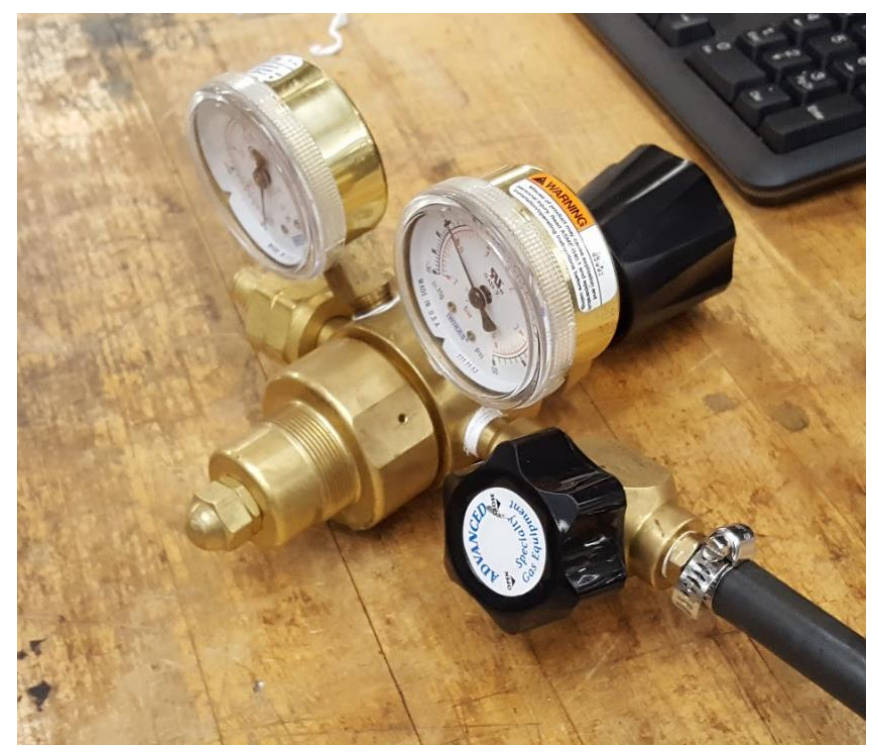

Figure 5: Pressure Regulator

The testing of the $20 \% \mathrm{H}$ synthetic gas mixture was also initially unsuccessful. During the first test, a pressure issue similar to the propane experiment occurred. The pressure was set to approximately $3 \mathrm{psi}$, at the outlet of the synthetic gas pressure vessel. However, at the inlet of the diaphragm, the pressure was spiking to $15+$ psi, past the precision of the pressure valve and then immediately dropping to 0 psi. A leak was discovered during this test and thought to be the problem. A gas leak tester was used to confirm the location of the leak in order to resolve this issue. This was accomplished by using nylon tape to secure and seal the tube and pressure gauge fittings. During this test, the valve pressure gauge reading was inconsistent with how much pressure was being released by the regulator valve (Figure 5). When attempting to refit the nylon tape on the pressure gauge, it was discovered that nylon had balled up in the opening of the gauge (Figure 6). Further testing noted that this was the cause of the inaccurate pressure readings. After each of these issues had been resolved, a second attempt to the start the engine was made. In this instance, the engine failed to engage. To encourage the engine starting process, a new pressure regulator was installed to the system as well as a starter fluid for this next test. 


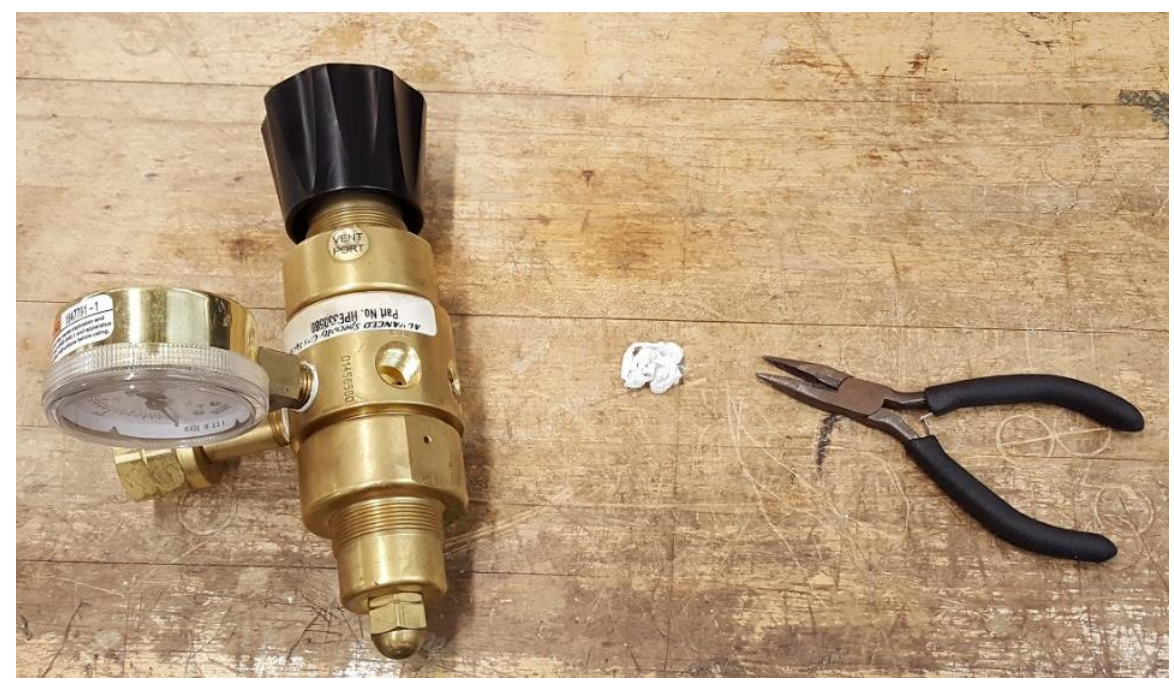

Figure 6: Balled Nylon

\section{Synthetic Gas Second Test:}

This phase of testing began by increasing the pressure of the synthetic gas mixture to increase the amount of fuel to the engine to assist the starting procedure. Testing started at 0 psi and was increased steadily by 1 psi intervals. At 15 psi, the engine began starting but would kickoff soon after. The diaphragm was primed before each attempt to ensure the presence of fuel inside the combustion chamber. The engine was running longer after priming but was still only running for a short period of time. The diaphragm was then held open to allow for a maximum amount of synthetic gas mixture to flow into the carburetor. The engine then ran without interruption. The pressure was increased until approximately 22 psi.

The $40 \% \mathrm{H}$ synthetic gas mixture was brought over, to determine its effectiveness in the engine. Since the $\mathrm{H}$ content in this mixture is approximately double that of the initial test, it was determined that the pressure should be dropped considerably. Thus, inlet pressure was dropped to approximately 6 psi. When the engine was started, it immediately backfired out the carburetor, indicating that the pressure was still too high. Accordingly, gradual increases from 1 psi was maintained during each test phase. The pressure was brought to approximately 12 psi where no significant performance increase was observed. The conclusion of the testing was to also increase the air flow necessary for the increased amount of fuel in order to run the engine more effectively. The diaphragm was also need to be replaced by a larger size in order to increase the synthetic gas and air mixture content entering the engine. 


\section{Synthetic Gas Test Setup:}

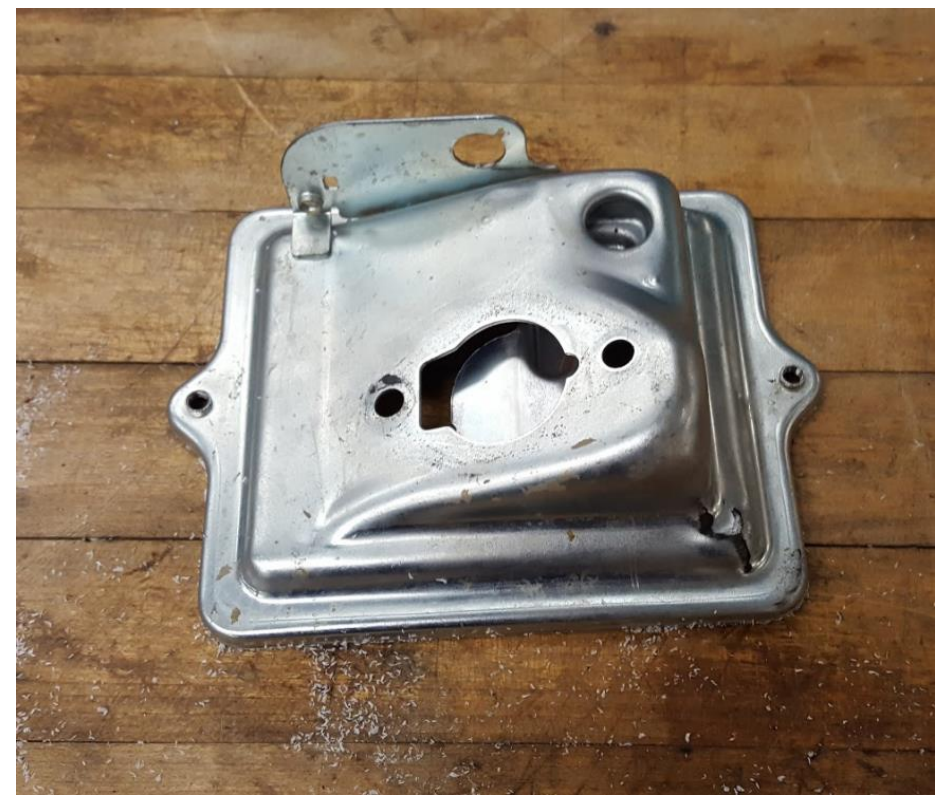

Figure 7: Carburetor Plate

To increase air flow to the engine, an air compressor was used to increase the air flow. First, the plate that the air filter attaches to, was removed (Figure 7). The distance between the two bolts was measured for recording. A caliper was then used to measure the diameter of the bolts. The measurement came to approximately a quarter-inch. The Gasket was then removed and brought to a hardware store so that a pipe flange could be used to add thread piping to the carburetor inlet. Two half-inch pipe nipples and a half-inch plumber's tee were also purchased. The gasket and flange were both secured to the carburetor with the quarter-inch bolts. Using nylon tape, the pipe nipple and a pressure gauge were secured to the plumber's tee. The pipe nipple was then secured to the pipe flange (Figure 8). An air-tube fitting was also attached to the other end of the plumber's tee. This setup, would enable a compressor to be attached to the carburetor to increase the air flow into the engine. The compressor would provide an increase of air flow that would be used with a pressure gauge to determine the most effective ratio between the synthetic gas and air mixture.

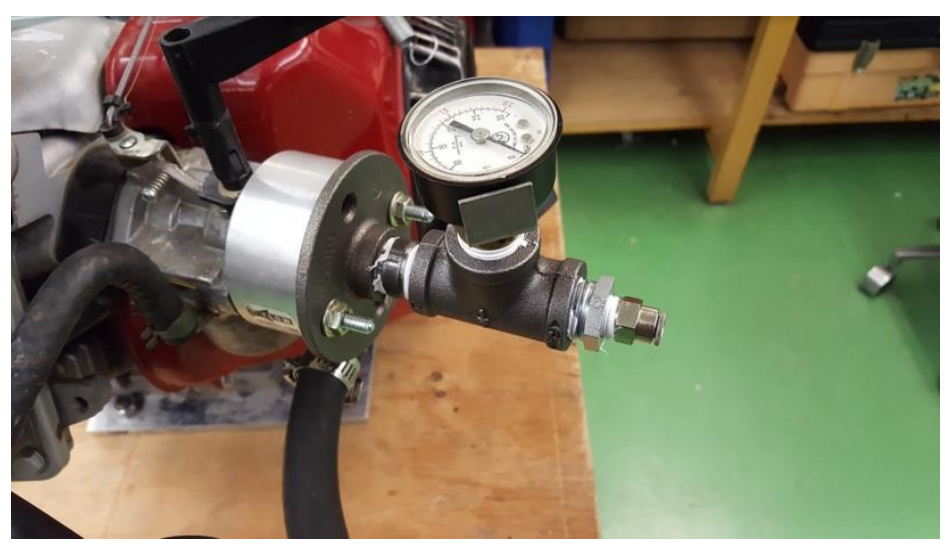

Figure 8: Engine Setup for Compressor 


\section{Testing and analysis:}

With the Compressed air fitting attachments installed, tests could then be ran with both synthetic fuels to analyze the different performance properties. For the test results, the performance characteristics were given a rating of $0-5$, this rating depended upon if the engine actually started at all with the fuel, how well it ran on the fuel, and how long it could run on the fuel with no user intervention.

The synthetic gas containing $20 \% \mathrm{H}$ did not perform well at any psi below 12 . However, when the psi was raised to anything above $13 \mathrm{psi}$ all the way to the max testing pressure of $25 \mathrm{psi}$, the engine showed substantial performance improvements. Next, once the fuel was switched to the $40 \% \mathrm{H}$ mixture, the performance of the engine increased across the psi test range. The engine started to show increased performance characteristics starting at $6 \mathrm{psi}$, as compared to the $12 \mathrm{psi}$ needed for the $20 \% \mathrm{H}$. This relationship in psi is caused by the composition of the fuel. Because the $40 \%$ syngas contains twice as much $\mathrm{H}$ compared to the $20 \%$, it will require roughly half as much pressure for the engine to start to show good performance.

\begin{tabular}{|r|r|c|c|}
\hline \multicolumn{4}{|c|}{ Synthetic Gas psi - Performance (Open Carburetor) } \\
\hline Test & psi & Performance (1-5) 20\% Hydrogen & Performance (1-5) $40 \%$ Hydrogen \\
\hline 1 & 1 & 0 & 0 \\
\hline 2 & 6 & 0 & 3 \\
\hline 3 & 12 & 3 & 5 \\
\hline 4 & 22 & 5 & 5 \\
\hline 5 & 25 & 5 & 5 \\
\hline
\end{tabular}

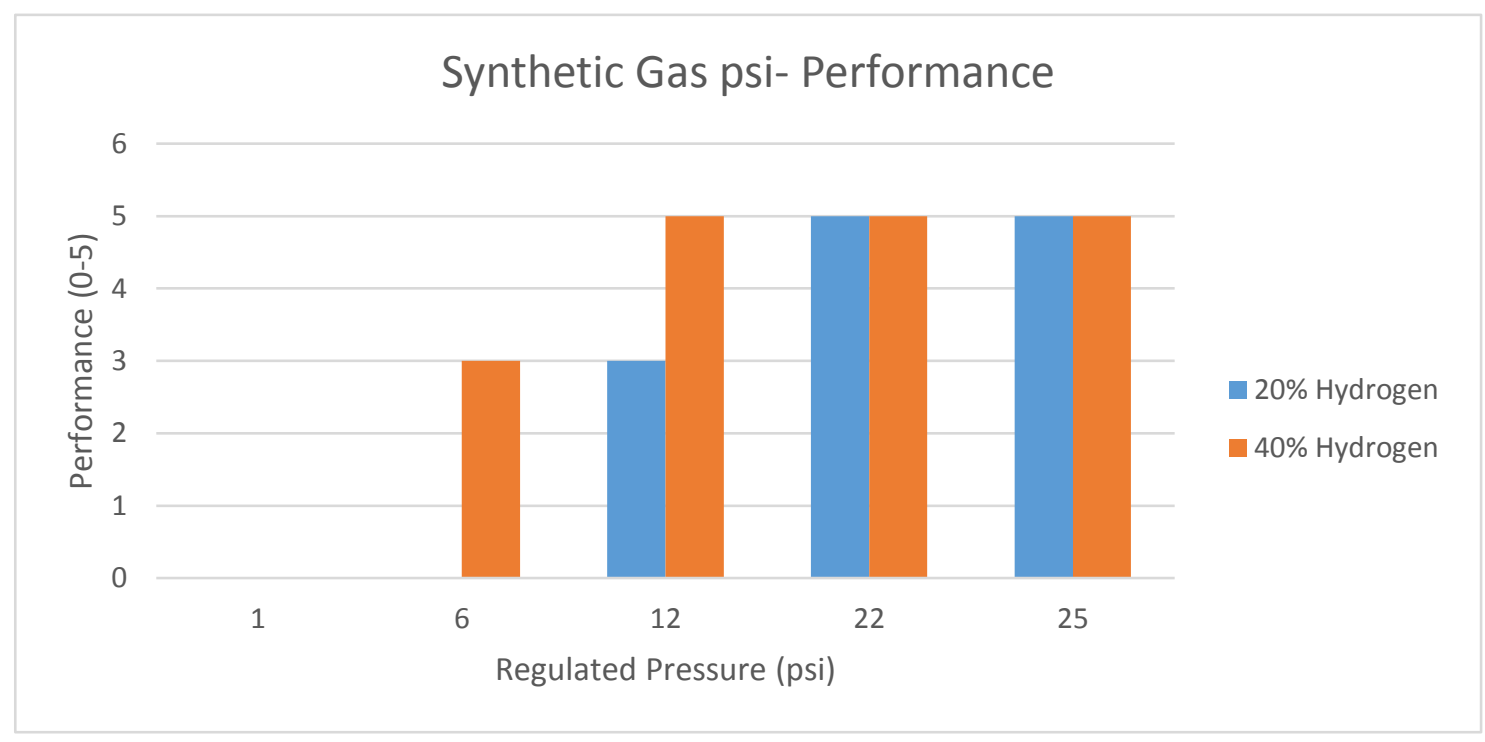




\section{Conclusions:}

- The results of the Synthetic Gas test concluded that an internal combustion engine was capable of running on the mixture. However, without enough air flow the engine was only capable of idling because when the fuel rate to the engine increases the engine tends to stall sue to the mismatch of fuel to air ratio. Thus, when throttled, the engine would kickoff. Throughout the tests, the group observed that a lack of air flow was the result of all the test failures. Therefore, it was concluded that by increasing the airflow to the engine, the performance of the engine would continue to increase.

- Student's feedback has confirmed that Practice oriented projects provides powerful applied learning tool that strongly enrich the education experience of the students.

\section{Bibliographic Information}

1. Y. Hung, H. Tawfik, D. Mahajan, "Durability and characterization studies of chromium carbide coated aluminum fuel cell stack". International Journal of Hydrogen Energy, 2015

2. J. J. Giner-Sanza, D. Boss, H. Tawfik, E. M. Ortegaa, V. Pérez-Herranza "Effect of CO2 poisoning on the parameters of a PEMFC empirical model" Farmingdale State College, NY 11735 - International Energy and Sustainability Conference 2015, November $12 \& 13,2015$

3. H. Tawfik, "Useful Cost Effective Energy form Biomass Waste", Farmingdale State College International Energy and Sustainability Conference - October 24, 2014

4. Glon, Ronan. "From Gasoline to Gasification, or why we don't power cars with wood today" Hemmings Motor News. 22 ${ }^{\text {nd }}$ Jan 2017. https://www.hemmings.com/blog/2017/01/22/from-gasoline-to-gasificationor-why-we-dont-power-cars-with-wood-today/ Accessed Feb. 2017.

5. "An in-depth Introduction to Automobiles." Jim 4x4- Web. Feb. 2017. http://www.jim4x4.com/images/auto-articles-images/carburetor.jpg

6. "An in depth Introduction to Automobiles-Power System", Jim 4x4-Web. Feb. 2017. http://www.jim $4 \times 4$. com/automobiles.html

7. "How a Regulator Works." Century Fuel Products. Web. Feb 2017. https://centuryfuelproducts.com/support/information/how-a-regulator-works

8. "Low Pressure Regulator." Century Fuel Products. Web. Feb 2017. https://centuryfuelproducts.com/brands/impco-replacement-parts/regulators/c-039-122-vaporizer-regulator 